D

Respiratory Dept, Wansbeck General Hospital, Newcastle upon Tyne, UK.

\title{
A sanguine experience
}

\section{Case Report}

Cite as: Aujayeb A

Macfarlane J, Fearby S, et al. Case report: A sanguine experience. Breathe 2015; 11: 213-217

\section{Case presentation}

A 68-year-old man attended the Accident and Emergency department with increasing breathlessness but no chest pain, sputum production or haemoptysis. He had recently returned from holiday in Spain and his general practitioner prescribed amoxicillin for a presumed chest infection. He was a diet-controlled type 2 diabetic on treatment for hypertension. He had a 40-pack-year smoking history and had lost $4 \mathrm{~kg}$ in weight. Examination revealed an obese man with normal blood pressure, sinus tachycardia at 100 beats $\cdot \mathrm{min}^{-1}$, with a respiratory rate of 26 breaths. $\mathrm{min}^{-1}$. His oxygen saturation was $96 \%$ on air. His white cell count was $11 \times 10^{9}$ cells. $\mathrm{L}^{-1}$ and $\mathrm{C}$-reactive protein was $92 \mathrm{mg} \cdot \mathrm{L}^{-1}$. Renal function and coagulation studies were normal.

\section{Task 1}

What does his chest radiograph (figure 1) show?
a. A large left pleural effusion
b. A large left pneumothorax
c. Left upper lobe collapse with volume loss
d. Left upper lobe consolidation

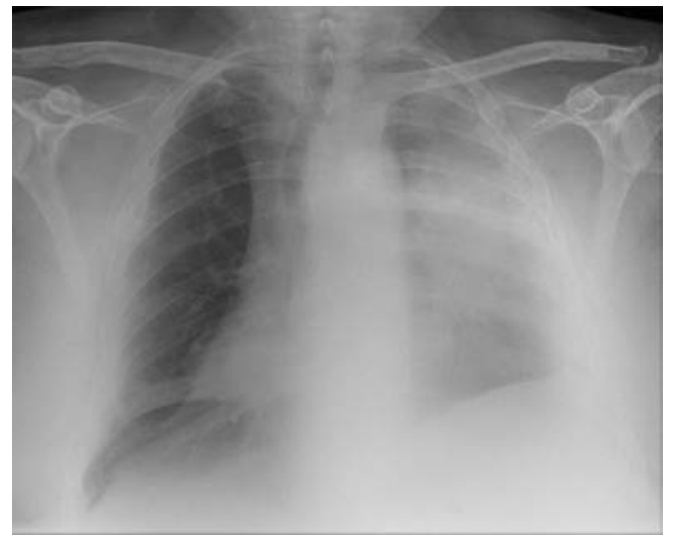

Figure 1 Chest radiograph. 


\section{Answer 1}

c. Left upper lobe collapse with volume loss

The admitting medical team felt that there was a "complete whiteout" of the left hemithorax and initially treated him for suspected severe community-acquired pneumonia with intravenous antibiotics and fluids, while arranging a respiratory opinion. Prophylactic low molecular weight
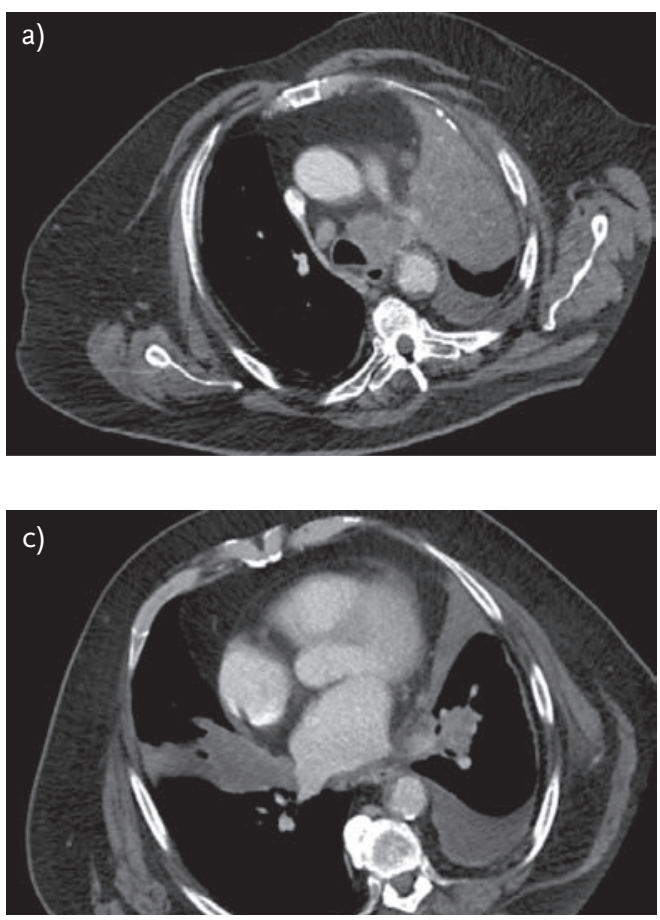

Figure 2 CT scans. heparin (LMWH) was also started. The respiratory team felt that an underlying malignancy may have been responsible for the radiographic appearances of left upper lobe collapse and suggested a computed tomography (CT) scan of the thorax. Figure 1 shows a "veil-like" opacity projected over the left lung field, a raised left hemidiaphragm with blunting of the left costophrenic angle consistent with left upper lobe collapse, volume loss and an associated pleural effusion.

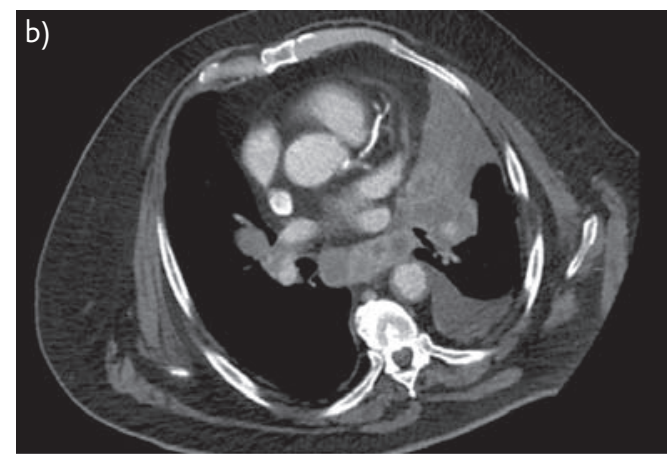

Task 2

What does his CT (figure 2) show?
a. Left upper lobe collapse
b. Large contralateral mediastinal nodes
c. Left pleural effusion
d. A large mass at the left hilum
e. All of the above 


\section{Answer 2}

\section{e. All of the above}

The CT scan showed a large left hilar mass coalescing with the left upper lobe collapse. There were associated large para-aortic, subcarinal, mediastinal and supraclavicular nodes, a single liver metastasis and a second separate mass in the right lung. Lung cancer staging was T4N3M1b.

It was interesting to note that a separate mass was present in the right lung (figure $2 \mathrm{c}$ ). He did have metastatic disease but this might represent a synchronous primary, although by strict definition, to diagnose this, we needed to prove that the second mass was of different histology to the primary mass or that it was of the same histology but with no mediastinal or metastatic spread [1].

While awaiting a bronchoscopy, the patient coughed up $\sim 600 \mathrm{~mL}$ of fresh blood in $12 \mathrm{~h}$, with worsening hypoxia. Repeat full blood count and coagulation studies were normal.

\section{Task 3}

What should form part of his immediate management?

a. Sit upright to improve oxygenation, large-bore intravenous cannulae, blood transfusions as required, stop LMWH

b. Lie on side of lesion, stop prophylactic $\mathrm{LMWH}$, administration of tranexamic acid

c. Urgent bronchoscopy and treatment with adrenaline/saline to tumour

d. Palliative approach with midazolam and morphine for symptom control

\section{Answer 3}

b. Lie on side of lesion, stop prophylactic $\mathrm{LMWH}$, administration of tranexamic acid

The patient was having massive haemoptysis, defined as coughing up anything between $100 \mathrm{~mL}$ and $600 \mathrm{~mL}$ of fresh blood in $24 \mathrm{~h}[2,3]$.

He was seen by the on-call medical team and sat upright. Two large-bore cannulae were inserted in case of exsanguination. Sitting upright runs the risk of the blood spilling over into the normal lung. "Drowning" by filling up the bronchial tree with blood tends to occur before any true haemodynamic instability due to volume loss. As such, the mainstay of treatment in massive haemoptysis is to protect the normal lung and try to stop the bleeding [4, 5].

The respiratory team felt that a palliative approach was too premature, but it was explained to him that his prognosis was poor with limited treatment options available. He agreed to a "do not resuscitate" plan. A treatment escalation plan was agreed to ensure his treatment was limited to level 2 care. Hypoxia precluded a bronchoscopy or transfer to the local cardiothoracic centre. Bronchoscopic strategies to control pulmonary haemorrhage include balloon tamponade, iced saline lavage, administration of a topical vasoconstrictor or coagulant, laser therapy and electrocautery [5].

The patient pointed to his left hemithorax when asked which side he felt the bleeding was coming from. Anecdotal experience suggests that patients with haemoptysis can often accurately indicate the side of the bleeding lesion. He was therefore positioned on his left side and tranexamic acid was administered intravenously. A pilot study evaluating the effect of tranexamic acid and the related antifibrinolytic agent aminocaproic acid included three patients with haemoptysis due to lung cancer [6]. All three patients experienced cessation of bleeding within 1-4 days without any recurrence. Patients received $1.5 \mathrm{~g}$ of intravenous tranexamic acid initially, followed by $1 \mathrm{~g}$ three times per day for a week after cessation of bleeding. The use of tranexamic acid in bleeding has been recognised for a long time [7] and tranexamic acid may reduce both the duration and volume of bleeding, with low risk of shortterm thromboembolic complications [8].

His haemoptysis and hypoxia improved over the ensuing days, and at bronchoscopy an organised clot was visualised in the left upper lobe bronchus with no endobronchial masses and a normal right bronchial tree. Left upper lobe lavage revealed no malignant cells on cytology. At endobronchial ultrasound examination, a large paratracheal node was sampled and histology demonstrated a poorly differentiated necrotic squamous cell carcinoma.

The patient's clinical condition slowly improved until 15 days into his admission, when overnight he developed acute dyspnoea with tachycardia at 120 beats $\mathrm{min}^{-1}$. Arterial blood gas sampling measured his arterial oxygen tension $\left(\mathrm{PaO}_{2}\right)$ at $7.0 \mathrm{kPa}$ on high flow oxygen via a reservoir bag, and an arterial carbon dioxide tension $\left(\mathrm{PaCO}_{2}\right)$ of $5.1 \mathrm{kPa}$. $A$ repeat chest radiograph showed no change.
Task 4

What is his alveolararterial oxygen tension difference $\left.(P \mathrm{~A}-\mathrm{aO})_{2}\right)$ ? 


\section{Answer 4}

His $P A-\mathrm{aO}_{2}$ is $71.625 \mathrm{kPa}$

The $P A-a_{2}$ is a measure of the difference between the alveolar concentration $(A)$ of oxygen and the arterial (a) concentration of oxygen. In room air (inspiratory oxygen fraction of 0.21 ) at sea level (atmospheric pressure of $760 \mathrm{mmHg}$ ) assuming $100 \%$ humidity in the alveoli, a simplified version of the equation is $21-\left(\left(\mathrm{PaCO}_{2} / 0.8\right)\right.$ $\left.-\mathrm{PaO}_{2}\right), 0.8$ being the respiratory quotient.

High flow oxygen delivers $\sim 85 \%$ oxygen, so $85-(5.1 / 0.8)-7=71.625$, which is significantly raised. While his $\mathrm{PA}-\mathrm{aO}_{2}$ was likely to be raised due to his cancer/effusion, such a disparity and the clinical picture points towards the possibility of a pulmonary embolus. The use of the $\mathrm{PA}_{\mathrm{A}-\mathrm{aO}}$ is a useful adjunct in diagnosis [9]. There are numerous case reports about tranexamic acid increasing the risk of pulmonary emboli $[10,11]$. In this case, the patient had other significant risk factors such as disseminated malignancy and a prolonged period of immobility.

\section{Task 5}

Which of the following are appropriate next courses of action?

a. Discuss risk/benefit of full anticoagulation with LMWH or intravenous unfractionated heparin with patient

b. Urgent CT pulmonary angiogram

c. Stop tranexamic acid and palliation of symptoms of breathlessness and agitation

d. Arrange urgent radiotherapy

e. All of the above

\section{Answer 5 \\ e. All of the above}

The patient understood that if left untreated, a large pulmonary embolus may prove fatal, but by treating it with anticoagulation, a major fatal haemoptysis was also more likely. He agreed to receive $\mathrm{LMWH}$ together with morphine for symptoms of dyspnoea and agitation. $6 \mathrm{~h}$ later, he had improved clinically and was able to safely lie flat briefly for a CT pulmonary angiogram. This confirmed large right-sided pulmonary emboli with associated right heart strain with reflux of contrast into the venous circulation (figure 3). The option of inferior vena cava filter insertion to prevent further embolic events was not available in our hospital, and he was too unstable to be transferred to an appropriate tertiary hospital. Over the following 2 days, urgent palliative radiotherapy to the leftsided tumour was arranged. After he had received a single fraction, further large volume haemoptysis recurred. $\mathrm{LMWH}$ was stopped and tranexamic acid restarted. The bleeding settled once more and he completed five fractions of radiotherapy. Slowly his oxygen saturations improved to $93 \%$ on air and he was discharged home on long-term full-dose LMWH with no recurrence of the haemoptysis.

He presented 3 weeks later with progressive respiratory failure and his symptoms were palliated according to his wishes.

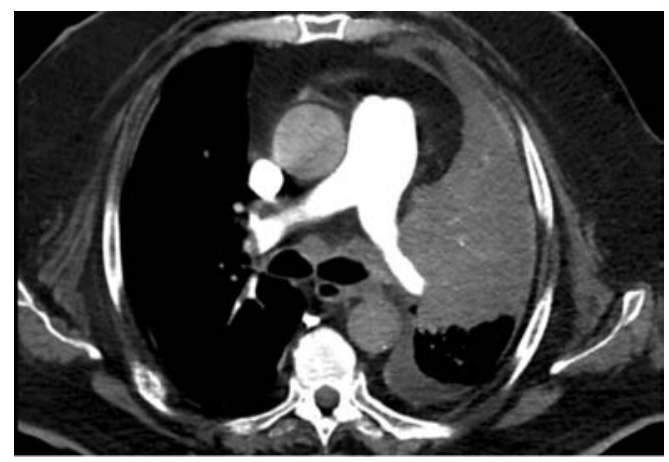

Figure 3 CT pulmonary angiogram. 


\section{Conflict of interest}

None declared.

\section{References}

1. Kozower BD, Larner JM, Detterbeck FC, et al. Special treatment issues in non-small cell lung cancer. Diagnosis and management of lung cancer, 3rd ed: American College of Chest Physicians evidence-based clinical practice guidelines. Chest 2013; 143: Suppl. 5, e369S-e399S

2. Jean-Baptiste E. Clinical assessment and management of massive hemoptysis. Crit Care Med 2000; 28: 1642-1647.

3. Corder R. Hemoptysis. Emerg Med Clin North Am 2003; 21 : 421-435.

4. Lordan JL, Gascoigne A, Corris PA. The pulmonary physician in critical care. Illustrative case 7: assessment and management of massive haemoptysis. Thorax 2003; 58 : 814-819.

5. Cahill BC, Ingbar DH. Massive hemoptysis. Assessment and management. Clin Chest Med 1994; 15: 147-167.

6. Dean A, Tuffin P. Fibrinolytic inhibitors for cancer-associated bleeding problems.J Pain Symptom Manage 1997; 13: 20-24.

7. Dunn CJ, Goa KL. Tranexamic acid: a review of its use in surgery and other indications. Drugs 1999; 57: 1005-1032.

8. Moen CA, Burrell A, Dunning J. Does tranexamic acid stop haemoptysis? Interact Cardiovasc Thorac Surg 2013; 17: 991-994.

9. Jones JS, Neff TL, Carlson SA. Use of the alveolar-arterial oxygen gradient in the assessment of acute pulmonary embolism. Am J Emerg Med 1998; 16: 333-337.

10. Krivokuca I, Lammers JW. Recurrent pulmonary embolism associated with a hemostatic drug: tranexamic acid. Clin Appl Thromb Hemost 2011; 17: 106-107.

11. Salam A, King C, Orhan O, et al. The great deception: tranexamic acid and extensive pulmonary emboli. BMJ Case Rep 2013; DOI 10.1136/bcr-2012-007808. 